\title{
Effect of Policy Measures Supporting the Agricultural Sector in Bulgaria After EU Membership
}

\section{Monika Sabeva*}

\section{Abstract}

The agricultural sector in Bulgaria has undergone significant changes over the past three decades. In the early 1990s, the land was shattered between small owners. This leads to a drastic decline in revenue and a reduction in productivity per unit area. In recent years, as a part of the Common Agricultural Policy of the European Union (EU), which is one of the most important EU policies, due to its high share in the Community budget almost $50 \%$, and also to the large territory and the large number of people directly affected by it, the country has implemented a number of measures aimed to support farmers and for land consolidation. They are targeted to supporting various activities and are aiming to improve the quality of production, reducing the cost per unit and improving the overall quality of life of farmers and the population in rural areas as a whole.

The main objective of the paper is to evaluate the overall impact of the implementation of policy measures targeted to stimulate the agricultural sector in Bulgaria in last ten years.
Keywords: agricultural sector, agricultural policy, Bulgaria.

JEL Code: Q1, Q10, Q15, Q18

\section{Introduction}

Dural areas in Bulgaria are heavily Ddependent on agriculture. The main problems of the sector are related to low productivity, fragmentation of land ownership, insufficient use of machinery and equipment, lack of managerial skills and knowledge, difficult access to external financing, insufficient irrigation and sewerage, poorly developed network of agricultural services and research units, as well as poorly developed breeding and selection activities.

Rural areas occupy $81 \%$ of the territory and $39 \%$ of the population of Bulgaria. Over the period 2007-2012, the population and density continue to decrease and the risk of depopulation of significant areas in rural areas is increasing, as the villages and small towns are most affected. Economic development of rural areas, measured by GDP per capita, is among the lowest in the EU (28\% of the EU average) due to under-utilization of the workforce, structural problems of economy and lower productivity. (RDP 2014-2020) Rural areas continue to lag behind urban areas in the country in their economic 


\section{Articles}

development. The rural economy has a low level of diversification. The development of non-agricultural sectors is hampered by worse investment opportunities, higher investment risk and costs, low incomes and high poverty, lower quality of workforce and public infrastructure, access to information, training, consultations and credits. The development of sectors that add value to primary products or use other local resources is poor.

There is a steady upward trend in the total amount of UAA after EU membership as a result of the intensification of land demand, the accumulation of less fertile land and the existence of incentives to expand farms, in order to accumulate more subsidies paid per dca. The ongoing consolidation of farms has a positive tendency to reduce the number of farms up to 1 hectare which are not eligible for SAPS payments. (Koteva, N. 2019) Still most of the Bulgarian farms are small which cause a number of problems, mainly in regard to the lack of sufficient machinery, the introduction of new technological solutions, the application of good agricultural practices and the development of efficient agriculture. (Koteva, N.; Fidanska, B., 2018)

The main obstacles to increasing the competitiveness of farmers are limited access to some production resources and high production costs; insufficient working capital; low mechanization of production; limited market access; competitive import of agricultural products, as well as the often changing regulatory framework; lack of sufficient experience in project management. (Borisov, P.; Radev, T.; Nikolov, D; 2015)

Despite the problems, agriculture remains an important sector for Bulgarian economy, especially with regard to employment. At the same time, the growth of productivity of labor in agriculture lags far behind that in industry and services. The large number of people employed in is a result of the large number of
Effect of Policy Measures Supporting the Agricultural

Sector in Bulgaria After EU Membership

small production facilities mainly for domestic consumption. (Popov, R., 2019)

In the period 1999-2000, Bulgaria faced the consequences of the Great Economic Crisis in 1997. The privatization or bankruptcy of state-owned enterprises, which started in 1998, led to massive redundancies of workers, some of which are redirected to the agrarian sector, starting to process their properties in rural areas without having the necessary knowledge and education for specific farming activities and without access to finance to help them improve and develop their farms. At the same time, the restitution of agricultural lands is completed, resulting in a significant fragmentation of land acquired by elderly people - the heirs of land owners prior to nationalization in the 1950s. Many small properties are leased to cooperatives, which are gradually being displaced by large farms that rent large areas of many villages in the area.

As a result in 1999, Bulgaria developed the first National Agriculture and Rural Development Plan 2000-2006 (NARDP), which is the first step in the country's affiliation to the European rural development policy. Rural Development Programme (RDP) is of particular importance for the country in the context of the role of agriculture in Bulgarian economy, the traditions in the sector and the favorable natural conditions for its development. (Preliminary assessment of the RDP 2007-2013, MAF)

Agriculture is a branch of Bulgarian economy, which, although significantly supported during the pre-accession period, continued to restructure after EU membership. This process is influenced by the Common Agricultural Policy of the Union. (Popov, R., 2019)

With Bulgaria's joining of the EU in 2007, the national market has become part of the internal market of the Community and 


\section{Articles}

Bulgarian producers and traders faced a number of challenges related to the size and structure of farms and agricultural exports. (AR, 2008) At the same time, new opportunities for support for agricultural producers are emerging under the Common Agricultural Policy (CAP) within the EU.

The Common Agricultural Policy is the first common policy of the European Community (EC) and has a key role in building the economic and political integration of the EU. Established in 1962, when EC founding members recover from a long period of food crisis, the implementation of CAP started by subsidizing the production of basic agricultural products in the name of providing food security. (CAP, 2007-2013)

For more than 50 years, CAP has been the most important common policy of the European Union (EU). The basic objectives of CAP laid out in the Treaty of Rome remain applicable over the years. CAP itself is going through continuous development and the reform process that began in the early 1990s leads to a new structure of the policy that reflects the changing socio-economic, environmental and political conditions with an impact on EU agriculture, as well as to changes in the agricultural sector, food sector, forestry, and in rural areas. (CAP, 2014-2020)

Issues related to the impact of CAP on the agricultural sector are extremely important and comprehensive. The organizational and economic structure of agriculture is a determining factor for the economic condition and competitiveness of farms but also a result of the applied national and common EU agricultural policy. (Koteva, N. 2019)

In 2013, CAP was amended in order to make a major contribution to achieving the objectives of the Europe 2020 Strategy by promoting smart, sustainable and inclusive growth. In this context, for the period 20142020 , there are three main objectives of CAP:
(1) effective food production, (2) sustainable management of natural resources and climate actions, and (3) balanced territorial development, and the existing instruments have been amended to meet these long-term policy objectives.

CAP forms a major part of the EU budget - 37,7\% of total EU expenses planned for the 2014-2020 period, which would be spent in three different ways: (1) income support of farmers and aid to comply with sustainable agricultural practices and (2) market support measures, which are the so-called "first pillar" of CAP and (3) Rural Development Programs (RDPs), which are the "second pillar" of CAP. They are multiannual, partly funded by the Member States and amount to almost $25 \%$ of the CAP budget. (CAP, 2014-2020)

After 2007 an accelerated rising of the relative share of created total output from the crop growing has been reported. Data for 2013 and 2014 do not report essential change of the trend. This process gives reason to draw the conclusion that in the first stage of CAP 2007-2013 the implementation part of structural changes in Bulgarian agriculture has been transformed in structural misbalances. (Yovchevska PI., 2017) The level of agricultural production for the period of EU membership has not significantly changed which indicates the stabilization of the sector, but at a relatively low level. (Popov, R., 2019)

Within the implementation of the second program and budget CAP period, there is a strong necessity for part of registered unfavourable processes to be restricted. CAP 2014-2020 implementation offers good opportunities for the balancing, although partial, of some disproportions. This requirement is related to the traditional presence and significance of livestock breeding and of the fruit and vegetable production in the country's economy. The development of sectors coupled with the 


\section{Articles}

production support within CAP 2014+ has an essential role for the solution of some socialeconomic problems in both national and in European aspect. (Yovchevska PI., 2017)

The 2007-2016 period is characterized by dynamic structural changes in farms. Restructuring of agricultural holdings leads to a change in the structure of UAA by groups of farms, depending on their size. There is a positive trend to increase the level of specialization and concentration of production, improving the market orientation of the farms. There is a tendency to reduce the number of farms. Reduction processes are most dynamic for holdings up to 2 hectares. A positive trend is the increase in the number of larger farms. It is expected that the outlined trend of decreasing the number of farms, mainly at the expense of small farms, will continue, but at a slower pace. (Koteva, N. 2019)

The main objective of the paper is to evaluate the overall impact of the implementation of policy measures targeted at stimulating the agricultural sector in Bulgaria in last ten years.

\section{Materials and methods}

The paper is based on a thorough review of reports, analysis and official documents as Agrarian reports, Rural Development Programs (RDPs), regulations and statistical data relating to the agricultural sector and to agricultural policy in Bulgaria. The analysis is based on available official documents and statistical information provided by the Ministry of Agriculture and Forestry.

Data related to changes in the agricultural sector and in total annual payments were reviewed and, on that basis, the main effects for this sector are identified.

National primary support schemes are weak, and by the end of 2006 , three separate funds direct the state support to the farmers, the tobacco growers and the persons
Effect of Policy Measures Supporting the Agricultural

Sector in Bulgaria After EU Membership

involved in the management forests and wood production: the State Fund for Agriculture, the Tobacco Fund and the Bulgarian Forests Fund. (Preliminary assessment of the RDP 2007-2013, MAF)

Having joined the EU in 2007, Bulgaria has to catch up with economic development and, in particular, with the development of the agrarian sector. At that time CAP was focused on three areas: (1) enhancing the competitiveness of the agricultural and forestry sectors; (2) improving the environment and the landscape and (3) improving the quality of life in rural areas and encouraging the diversification of their economy. (CAP, 2007-2013) The priority of MAF policy at the beginning of the period under review (2007) was to support voluntary consolidation by improving the legal framework and guidance for farmers, as well as to create incentives for the consolidation and transformation of the semi-market farms into market ones, as well as to encourage investments in physical and human capital. (RDP 2007-2013)

CAP implementation after 2007 leads to almost complete marginalization of fruits' and vegetables' productions. Technological requirements of this intensive production, the lack of preparation of the sector for the strong competition on the part of other EU member states, the invasion of supermarkets in the retail trade, the presence of lot of small farms in the sector of fruits and vegetables, the disloyal competition from neighbouring countries, the lack of associations of producers of fruits and vegetables are some of the factors that brought about this state. The share of fruit production in the agricultural total output in the period 2006-2012 has decreased twice. At the end of period there were just symbolic values. To the mentioned reasons we could add the process of ending the activity for a big part of orchards and the relatively small 


\section{Articles}

share of new plantations, replacing the old ones. (Yovchevska PI., 2017)

The National Strategic Plan for Rural Development (NSPRD) of Bulgaria sets the following general objectives for the period 2007 - 2013: (1) developing a competitive and innovation-based agriculture, forestry and food industries; (2) conservation of natural resources and environment in rural areas and (3) improving the quality of life and diversification of employment opportunities in rural areas.

The RDP has four axes with the corresponding general objectives as follows: (1) Axis 1 "Improving competitiveness in the agricultural and forestry sector" with general objective "Development of competitive and innovation-based agriculture, forestry and agro-food industries"; (2) Axis 2 "Improving the environment and nature" with general objective "Conservation of natural resources and the environment in rural areas"; (3) Axis 3 "Quality of life in rural areas and diversification of the rural economy" with general objective "Improving the quality of life and diversification of employment opportunities in rural areas" and (4) Axis 4 "Leader" with general objective "Building local capacity and improving local governance". Specific measures are aimed to achieve these objectives. (RDP 2007-2013) Implementation of these objectives contributes to the improvement of the agricultural and forestry sectors and the quality of life in rural areas.

Part of the measures, mainly under the RDP, are aimed at overcoming the existing obstacles to the development of small farms, supporting their restructuring and turning them into modern and competitive agricultural production units. As a result of the dynamically running processes, the structure of agricultural holdings changes. Due to the small size of the farms, it is not possible to ensure full annual employment, which requires a majority of farmers to supplement their income from other activities. Despite the decline in the workforce and the amount of labor input, the labor intensity in small farms remains extremely high. (Koteva, N.; Fidanska, B., 2018)

The measures implemented during the first programming period under Axis 1 have a modest contribution to increasing the competitiveness of agriculture and forestry. The lowest contribution is from the measures 122 "Improving the economic value of forestry" and 142 "Establishing organizations of producers". The highest contribution to addressing these problems is related to Measures 141 "Support to semi-subsistence farms", 121 "Modernization of agricultural holdings" and 112 "Young farmers". (Borisov,

\section{P.; Radev, T.; Nikolov, D; 2015)}

Among these problems there are the providision of healthy food with proven origin, enlargement of the range of goods with opportunities to create added value and of products having high exportation potential. The support for these intensive productions ensures working places and decreases migration processes impact. The support for the vulnerable/sensitive sectors should be realized through all eligible schemes and measures, with the idea that the made investments have high return rate. (Yovchevska PI., 2017)

The total amount of payments for agriculture for the 2007-2013 programming period is $9070,84 \mathrm{mln}$. BGN. They are structured in five major groups (Graph 1):

(1)Direct payments per area with a total amount of the aid 3586,12 mln. BGN;

(2) National additional payments and state aid with a total amount of the aid 1256,48 mIn. BGN;

(3) Payments under the schemes and measures of the Rural Development Programme (RDP) with a total amount of 


\section{Articles}

the aid $3834,62 \mathrm{mln}$. BGN;

(4) Payments under the schemes and measures of the Operational Programme for Development of Fisheries Sector
Effect of Policy Measures Supporting the Agricultural

Sector in Bulgaria After EU Membership

(OPDFS) with a total amount of the aid $73,85 \mathrm{mln}$. BGN;

(5) Agricultural Market Mechanisms with a total amount of the aid 319,77 mln. BGN.

\title{
Payments under schemes and measures 2007-2013, mln. BGN
}

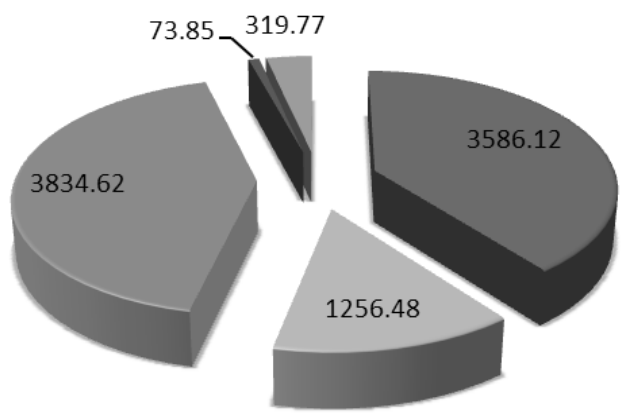

\author{
Direct payments per area \\ $\square$ National additional payments and \\ state aid \\ $\square \operatorname{RDP}(2007-2013)$ \\ 口 OPDFS (2007-2013) \\ $\square$ Agricultural Market Mechanisms
}

Chart 1: Payments for agriculture for the $2007-2013$ programming period, $\mathrm{mln}$ BGN Source: Based on data from Agrarian reports, 2008-2014

In order to ensure policy consistency, the implementation of the Area Payment Scheme continues throughout the 2014-2020 programming period. In order to extend the scope of the farmers eligible for the scheme, the minimum size of eligible farm is reduced from 1 ha to 0,5 ha, with a minimum parcel size of 0,1 ha. (AR, 2014, 2015, 2016, 2017, 2018) In line with the objectives of the EU's Rural Development Policy, the 2014-2020 RDP has three objectives: (1) improving the competitiveness and balanced development of agriculture, forestry and manufacturing; (2) conservation of ecosystems and sustainable management and the use of natural resources in agriculture, forestry and food industry, prevention of climate change and adaptation to it, and (3) socio-economic development of rural areas, creating new jobs, reducing poverty, social inclusion and a better quality of life. The programme has three specific objectives, five thematic priorities and sixteen priority areas. In addition, to achieve the objectives of the thematic priorities, interventions are planned, including stimulation of innovation and the transfer of knowledge and information for addressing all the priorities / priority areas of the Community's rural development policy. (RDP 2014-2020)

The current programming period (20142020) provides more flexibility for managing the sector's financial flows and, in particular, targeting them towards effective resource management. Transferring funds from first pillar (Direct Payments) to second pillar (RDP) enables more resources to be allocated to measures and objectives related to increasing the production capacities. At the same time, funds from the national budget should also be managed in order to achieve concrete results rather than just income maintenance.

The total amount of payments for agriculture for the 2014-2018 programming period is $12238,45 \mathrm{mln}$. BGN. They are structured in five major groups, corresponding to those from the previous programming period (Graph 2):

(1) Direct payments per area with a total amount of the aid $7677,46 \mathrm{mln}$. BGN;

(2) National additional payments and state aid with a total amount of the aid 1090,16 mln. BGN; 


\section{Articles}

(3) Payments under the schemes and measures of the Rural Development Programme (RDP) with a total amount of the aid 2817,01 mln. BGN;

(4) Payments under the schemes and measures of the Programme for Maritime Affairs and Fisheries (PMAF) with a total amount of the aid 242,91 mln. BGN;

(5) Agricultural Market Mechanisms with a total amount of the aid $410,90 \mathrm{mln}$. BGN.

\section{Payments under schemes and measures 2014-2018, mln. BGN}

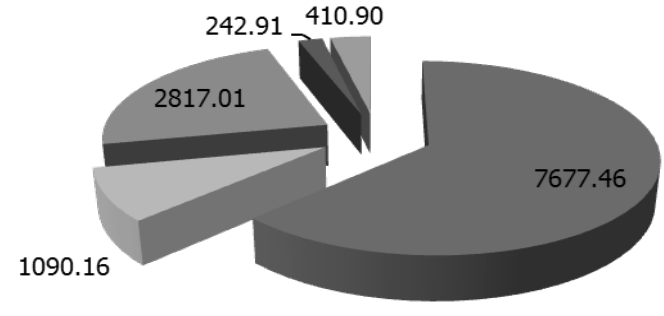

Chart 2: Payments for agriculture for the 2014-2018, mIn BGN

Source: Based on data from Agrarian reports, 2014-2018

That makes the total payments for agriculture for the period 2007-2016 equal to 19699,6 mln. BGN (Chart 3), distributed as follows:

(1) $9724,78 \mathrm{mln}$. BGN - Direct payments per area;

(2) $2346,64 \mathrm{mln}$. BGN - National additional payments and state aid;

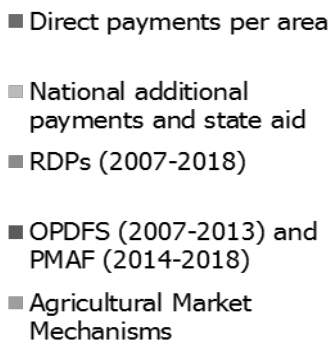

Payments under schemes and measures

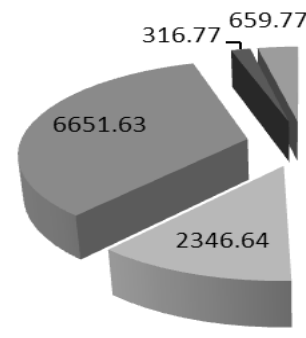
2007-2018, mln BGN

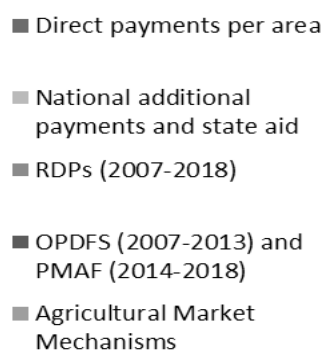

Direct payments per area

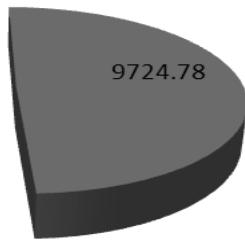

(4) 316,77 mln. BGN - Payments under the schemes and measures OPDFS and PMAF;

(5) 659,77 mln. BGN - Agricultural Market Mechanisms.

Chart 3: Payments for agriculture for the 2007-2018, mIn BGN Source: Based on data from Agrarian reports, 2008-2018

\section{Results and discussion}

Despite the variations in individual groups of schemes and measures providing funding, the total amount allocated for the agricultural sector registers stable growth up to 2015 and a decrease after 2016 (Chart 4). That is due to the closure of payments for the previous programming period in 2015 and the opening of procedures for the current period, so the 


\section{Articles}

approval of some of the applications is still in progress at that time, as well as to the normative changes introduced at the beginning of the current programming period. However, the growth of funds for the period is huge - more than 6500 times.
Effect of Policy Measures Supporting the Agricultural Sector in Bulgaria After EU Membership

In connection with the closure of the 2007-2013 programming period and in view of the deadline for the eligibility of expenditure - 31.12.2015, no contracts under OPDFS were concluded in 2017. By June 2018 - a total of $176,820,381,15$ BGN is paid under the measures for Fisheries.

Payments under schemes and measures 2007-2018, mln. BGN

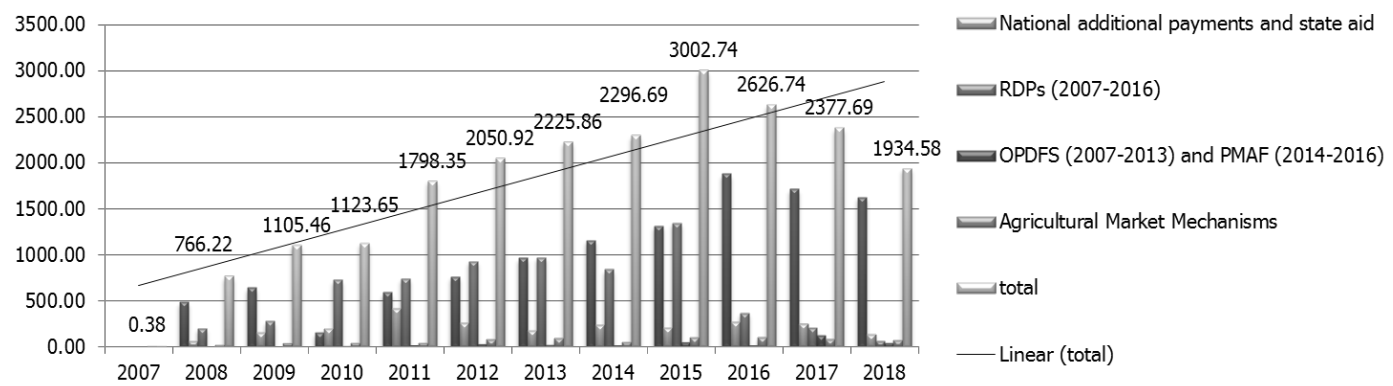

Chart 4: Payments for agriculture for the 2007-2018*, mIn BGN

Source: Based on data from Agrarian reports, 2008-2018*

* Available data for 2018 are preliminary and there is still no published information for some of the measures, so the 2018 information is not taken into account when the overall trend is discussed.

According to the Agricultural Census 2010, there were 370220 agricultural holdings in Bulgaria and according to the intermediate researches on the structure of agricultural holdings in Bulgaria (MAF) in 2013 and 2016 252900 holdings in 2013 and 201014 holdings in 2016. The breakdown of agricultural holdings by size reveals an interesting characteristic of the Bulgarian population of farms: it is dominated by two opposite size classes but in different respects. In 2010, $80 \%$ of the holdings had between 0 and 2 ha of agricultural land but accounted for only $3 \%$ of the UAA. On the other hand just $1 \%$ of holdings were very big with at least 100 ha of agricultural land, but these made up $82 \%$ of the total Bulgarian UAA (Chart 5). (MAF, Agrostatistics Department)

Number of holdings and UAA by UAA size classes, \%

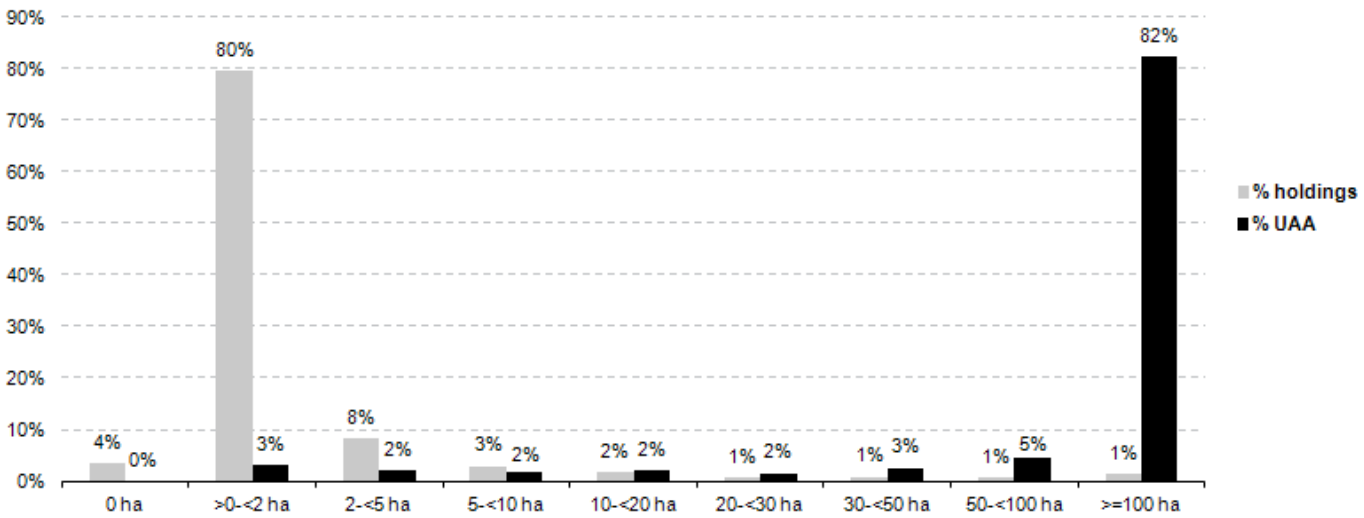

Chart 5: Agricultural holdings and UAA, Agricultural Census 2010,\%

Source: MAF, Agrostatistics Department 


\section{Articles}

The agricultural structure in Bulgaria is bipolar. The share of farms with less than 5 ha of UAA is very high (91\%), but they have a very small share in the UAA $(5.2 \%)$ and the standard production volume $(8.7 \%)$. In recent years there has been a favorable trend to increase the average agricultural and economic size of farms, but there is also an increasing concentration of land in the largest farms with over 100 ha. (RDP 2014-2020)

Agricultural holdings in Bulgaria (Chart 6; Table 1) in 2016, when the last intermediate research was conducted, are 201014. The

utilized agricultural area (UAA) is 37955343,5 dca and is distributed in 184448 farms. About 16566 farms do not hold UAA. As a result, the average UAA per holding has increased twice.

The number of agricultural holdings (Table 2) with UAA up to 10 ha is constantly decreasing and of those with UAA 10 to 50 ha or over 50 ha has increased. Significant growth was also registered in the number of farms without UAA. (MAF, Agrostatistics Department, FSS'2013 and 2016)

\section{Agricultural Holdings in Bulgaria, censuses 2003-2016, number}

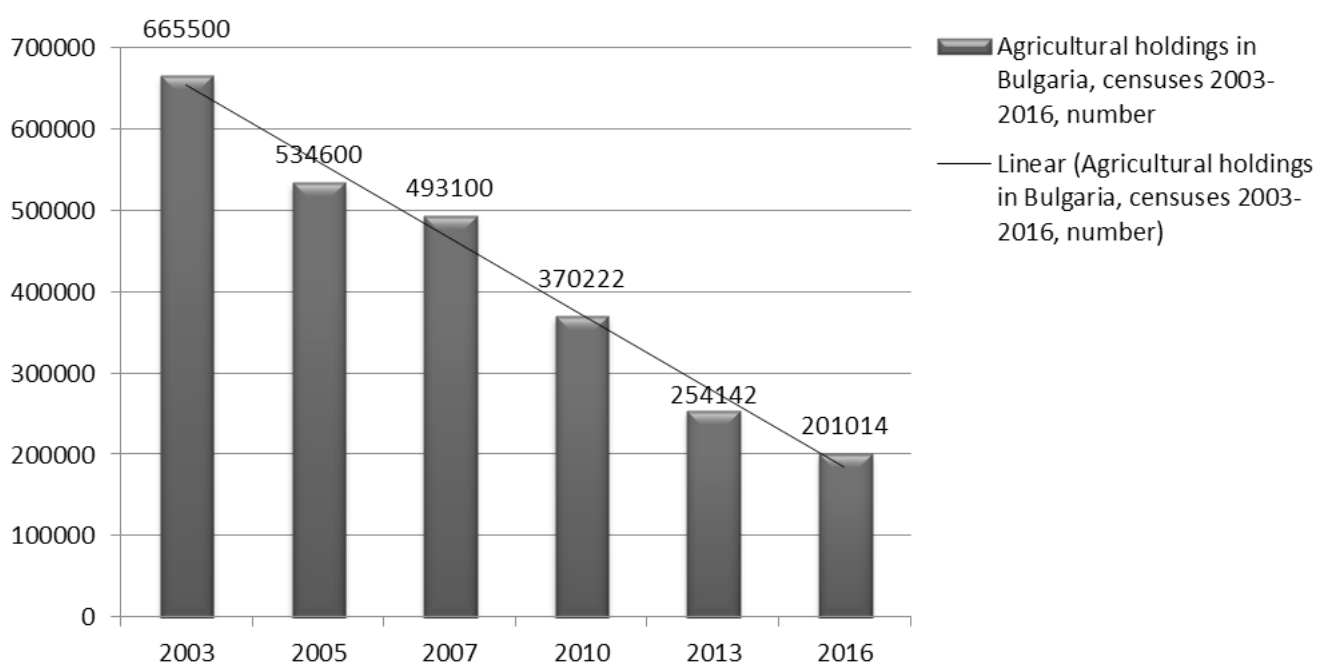

Chart 6: Agricultural holdings in Bulgaria, number

Source: MAF, Agrostatistics Department, Research on the structure of agricultural holdings in Bulgaria in 2013 and 2016

Table 1: Structure of agricultural holdings, change for the period 2010-2016

\begin{tabular}{|c|c|c|c|c|}
\hline & $\begin{array}{c}\text { Agricultural holdings } \\
\text { (incl. without UAA) }\end{array}$ & $\begin{array}{c}\text { Agricultural } \\
\text { holdings with UAA }\end{array}$ & UAA, dca & $\begin{array}{c}\text { Average UAA } \\
\text { per holding, } \\
\text { num }\end{array}$ \\
\hline 2010 & 370222 & 357100 & 36169600 & 101.3 \\
\hline 2013 & 254142 & 243400 & 37083300 & 152.4 \\
\hline 2016 & 201014 & 184448 & 37955343.5 & 205.8 \\
\hline $\begin{array}{c}\text { Change 2010- } \\
2016, \%\end{array}$ & $-46 \%$ & $-48 \%$ & $5 \%$ & $103 \%$ \\
\hline
\end{tabular}

Source: MAF, Agrostatistics Department, Research on the structure of agricultural holdings in Bulgaria in 2013 and 2016 
Table 2: Distribution of agricultural holdings by classes of utilized agricultural area (UAA), change for the period 2010-2016

\begin{tabular}{|c|c|c|c|c|c|c|c|}
\hline $\begin{array}{c}\text { Distribution of } \\
\text { agricultural holdings by } \\
\text { classes of utilized } \\
\text { agricultural area (UAA) }\end{array}$ & 0 ha & $0-1$ ha & $1-2$ ha & $2-10$ ha & $10-50$ ha & over 50 ha & total \\
\hline 2010 & 13148 & 248015 & 46944 & 41124 & 12828 & 8163 & 370222 \\
\hline 2013 & 9548 & 143502 & 40141 & 38689 & 13402 & 8860 & 254142 \\
\hline 2016 & 16566 & 102608 & 27304 & 29741 & 15343 & 9452 & 201014 \\
\hline change $2010-2016$ & $26 \%$ & $-58 \%$ & $-42 \%$ & $-28 \%$ & $20 \%$ & $16 \%$ & -46 \\
\hline
\end{tabular}

Source: MAF, Agrostatistics Department, Research on the structure of agricultural holdings in Bulgaria in 2013 and 2016

For the 2007-2018 period, the share of - respectively by $4 \%$ and $1 \%$ for the period agricultural land and UAA remains roughly unchanged - with an insignificant decrease (Chart 7).

\section{Agricultural land and used agricultural land,\%}

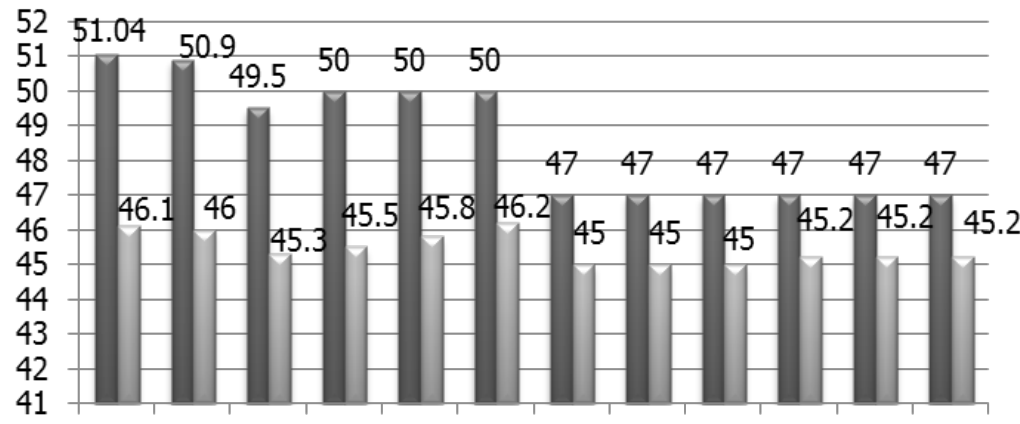

200720082009201020112012201320142015201620172018

Graph 7: Agricultural land and used agricultural land,\% of the territory

Source: Based on data from Agrarian reports, 2008-2018

Along with the decrease in the number of farms, this means that the average farm size increases, which is an indicator of progress in the process of land consolidation. Still the percentage of small farms with an average size of up to 2.0 ha and an average production volume of up to 2000 EUR remains high.

Most of the farms in Bulgaria have low agricultural diversity and their structure is reduced to the cultivation of 1-2 crops. Only $1.1 \%$ of the farms are engaged in nonagricultural activities, with $5.5 \%$ for the EU.

The first main effect of implemented measures and schemes for support of agriculture is the reduction in the number of farms in favour of their size. This trend is extremely favorable as large farms have better opportunities to apply new technologies, more easy access to credits, and have the opportunity to apply good management and production practices, which could make them competitive on the international market.

The price of agricultural production marks a total increase of about $21 \%$ for the period (Chart 8), though there are some fluctuations over the years. The gross value added in agriculture at basic prices is increasing as well with a total of around $30 \%$ for the period (Chart 9). There is a sharp increase in 2007 , when the implementation of CAP in Bulgaria as a new EU member state is set out, followed by a sharp decrease for the next year and by a constant increase since then. 


\section{Agricultural production, mln BGN}

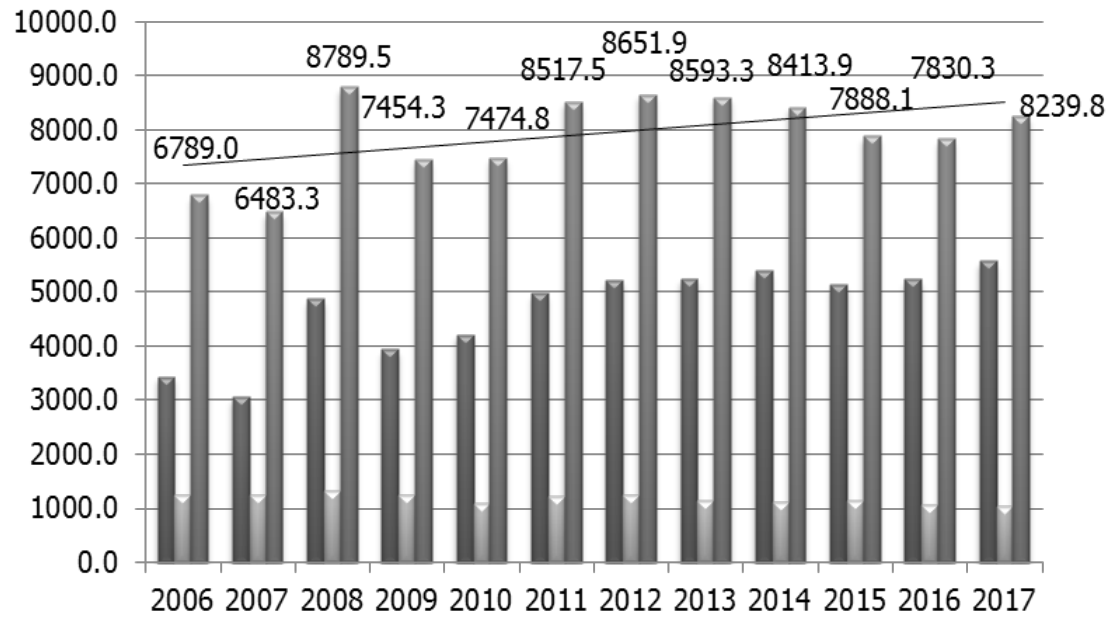

total crop

production

$\smile$ farm animals

$\square$ total agricultural production

- Linear (total agricultural production)

Chart 8: Agricultural production, mIn BGN

Source: Based on data from Agrarian reports, 2008-2018

Gross value added in agriculture at basic prices, mln. BGN

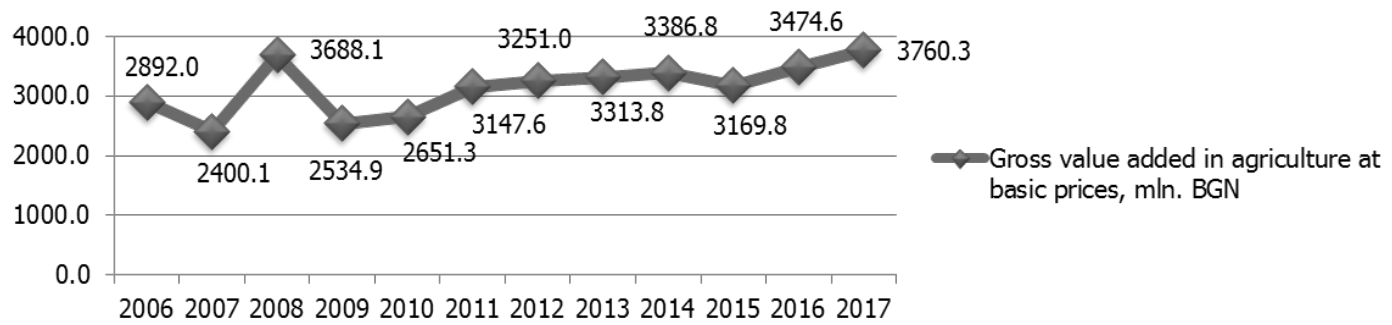

Chart 9: Gross value added in agriculture at basic prices, mIn BGN

Source: Based on data from Agrarian reports, 2008-2018

The price of agricultural production and the gross value added in agriculture at basic prices almost stagnate between 2012 and 2014 as this is the transition period between two planning periods. This phenomenon is observed and could be traced in years before. During this time, no new calls were announced and open, consequently no possibilities for producers to diversify the funding portfolio and and to implement new projects.

The second main effect of the implemented measures and schemes for support of agriculture is the growth of agricultural production and the gross value added in agriculture at basic prices due to the improved opportunities for production, processing and distribution of the production of the sector.

For the period 2007-2018 the average price of agricultural land (in BGN/dca) increased by more than three times and the price of rental agreements with agricultural land (in BGN/ dca) - by two times (Chart 10). As the price is a result of supply and demand and the supply of land is approximately constant, this leads to the conclusion that the demand is increasing as well, that is due to the developments in the sector and the growing interest in it. 


\section{Average price of agricultural land and of rental agreements with agricultural land, BGN/dca}

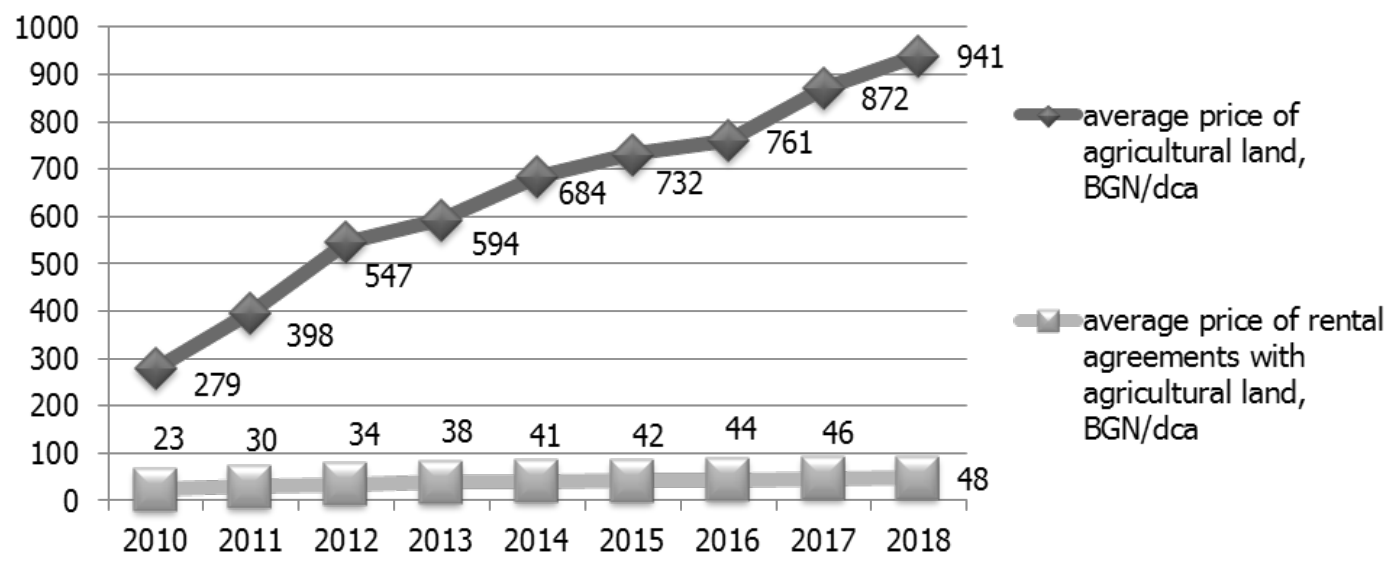

Chart 10: Average price of agricultural land and of rental agreements with agricultural land, BGN/dca Source: Based on data from Agrarian reports, 2008-2018

The number of registered farmers per year for the period marks a total increase of almost $10 \%$ although there is a sharp decline in 2010 after which their number is slightly increasing up to 2017 and in 2018 there is a slight decrease (Chart 11). The significant increase during the period 2007-2010, coincides with Bulgaria's the EU accession and the start calls.

of implementing the measures and support mechanisms of the Community. There is also a period of stagnation between 2010-2012, mainly due to the interim reporting period and the difficulties in opening subsequent procedures for the announcement of new

\section{Registered farmers, num.}

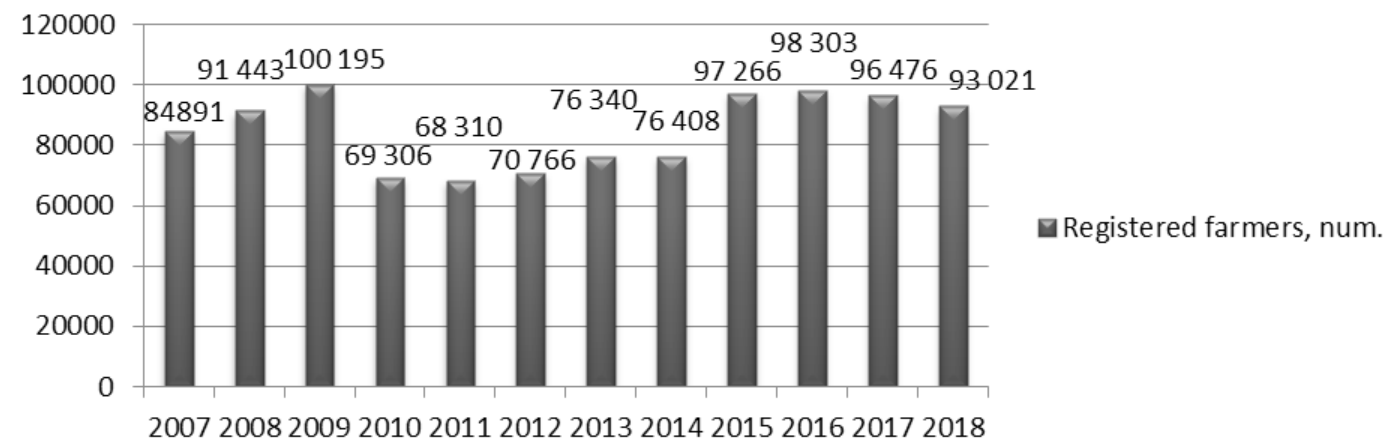

Chart 11: Registered farmers, number

Source: Based on data from Agrarian reports, 2008-2018

The third main effect of implemented measures and schemes for support of agriculture is the increase of land price and the number of registered farmers due to the growing attractiveness of the sector.

\section{Conclusion}

Bulgaria has long-standing traditions in agricultural production and favorable opportunities for developing the agrarian 


\section{Articles}

sector and taking a decent market place in the EU and in the world. Despite the significant support by CAP, the sector is still facing significant problems and many factors are limiting the development of plant production, such as the lack of financial resources to consolidate and modernize production, poor producer interest in association with producer organizations, the lack of arrangements between producers and traders for the realization of final products, lower payment for labor, low interest in production insurance and development of monocultural agriculture, especially grain and oil crops, at the expense of sectors with higher added-value, such as livestock, fruit and vegetables.

The payments for agriculture over the last decade has increased more than 6500 times. Despite the considerable financial support that Bulgarian agriculture receives, the sector does not use its competitive advantages. Currently, direct support schemes for farmers do not stimulate productivity and investment growth, resulting in the added value of the sector being kept low and even declining in real terms.

There is also a tendency of increasing in the average price of agricultural land, the price of rental agreements with agricultural land, the price of agricultural production and the gross value added in agriculture at basic prices due to the growing attractiveness of the sector.

For the 2007-2018 period, there is a decrease in the number of farms but an increase in the average farm size. Still the percentage of small farms with an average size of up to 2.0 ha and an average production volume of up to 2000 EUR remains high. The average economic size of farms in Bulgaria is 6,847 Euros, which is 3.7 times lower than the EU average.

The agricultural structure in Bulgaria is bipolar. The share of farms with less than 5 ha of UAA is very high (91\%), but they have a very small share in the UAA (5.2\%) and the standard production volume (8.7\%) and there is an increasing concentration of land in the largest farms with over 100 ha. The extreme polarization of farms in terms of size - a large number of holdings with a small part of the land and a very small number of holdings with more than 2/3 UAA - requires two different approaches to their development as the support for large farms equipped with modern technology can be directed to stimulate them to produce large quantities of raw materials for the processing industry

Most of the farms in Bulgaria have low agricultural diversity and their structure is reduced to the cultivation of 1-2 crops. Only $1.1 \%$ of farms are engaged in non-agricultural activities, with $5.5 \%$ for the EU.

There are three main effects of the implemented measures and schemes for support of agriculture: (1) the reduction in the number of farms in favour of their size; (2) the growth of agricultural production and the gross value added in agriculture at basic prices and (3) the increase of land price and the number of registered farmers due to the growing attractiveness of the sector.

\section{References}

Agrarian Report (various years from 2007 to 2018), MAF

Common agricultural policy (CAP), 20142020, EU

Eurostat, statistical data

Government Program for Sustainable Development of the Republic of Bulgaria for 2014-2018

Preliminary assessment of RDP, 2007-2013, MAF

RDP 2007-2013

RDP 2014-2020 


\section{Articles}

Regulation (EU) No 1307/2013 (Article 9) of the European Parliament and The Council, 17 December 2013 establishing rules for direct payments to farmers under the CAP support schemes and repealing Regulation (EC) No 637/2008 of The Council and Regulation (EC) No 73/2009 of The Council and the relevant national legislation defining "active farmer"

Institute for Market Economics (IME), analyses and reports http://ime.bg/en/

Borisov, P, Radev, T, Nikolov, D. Effect of the measures under the RDP 2007-2013 on the competitiveness of the agricultural sector; Economics and Management of Agriculture, 60, 2/2015 / lkonomika i upravlenie na selskoto stopanstvo (Bg); p. 43-52

Koteva, N. Changes of the Organizational and Economic Structure of Bulgarian
Effect of Policy Measures Supporting the Agricultural

Sector in Bulgaria After EU Membership

Agriculture. Economics and Management of Agriculture / Ikonomika i upravlenie na selskoto stopanstvo, 64/2/2019, 3-22 (Bg)

Koteva, N, Fidanska, B. Development and Support of Small Farms in Bulgaria; Economics and Management of Agriculture / Ikonomika i upravlenie na selskoto stopanstvo (Bg), 63, 1/2018; pp. 3-18

Popov, R. Structural Changes in Bulgarian Agriculture in the Period 2007-2017. Economics and Management of Agriculture I Ikonomika i upravlenie na selskoto stopanstvo, 64/1/2019, 3-22 (Bg)

Yovchevska PI. First program and budget period of CAP 2007-2013 in Bulgaria: problems and challenges. Economics of Agriculture. Vol. 17. Issue 1.; 2017 p. 86-95 